\title{
Josep Estalella i Graells (1879-1938): el científic que va renovar l'educació secundària
}

\author{
Jaume Baltà i Moner* \\ Salvador Domènech i Domènech ${ }^{* *}$
}

\section{Resum}

Pocs docents són recordats més enllà del temps vital del seu alumnat. I encara menys els honorats dins el camp de la Història de l'Educació. Un d'aquests professors privilegiats és el doctor Josep Estalella (1879-1938), per les aportacions originals envers la millora de la metodologia i la utilització de recursos didàctics. De l'educació activa en va fer l'objectiu de la seva vida. Un tarannà voluntariós i un vigor dirigent van fer possible el canvi pedagògic a l'educació secundària catalana mitjançant el funcionament de l'Institut-Escola, paradigma de la renovació. Una de les seves obres, Ciencia Recreativa..., cent anys després de la publicació, encara és per al professorat una valuosa eina didàctica per aconseguir l'objectiu inicial: cridar i captar l'atenció de l'alumnat mitjançant el joc intel·lectual.

Paraules clau

Josep Estalella, Institut-Escola, educació secundària, ciència, pedagogia, recreacions científiques, Història de l'Educació.

Recepció original: 05 de febrer de 2019

Acceptació: 04 de setembre de 2019

Publicació: 20 de gener de 2020

\section{Introducció}

El 2018 es va commemorar el vuitantè aniversari de la mort del doctor Josep Estalella i, al mateix temps, el centenari de I'Instituto-Escuela de Madrid, on ell en va ser professor i director des del 1919-21. A més, el 2019 ha fet cent quaranta anys del seu naixement. Les remembrances no deixen de ser bones ocasions per parlar de fets, institucions i personalitats, com és el cas de l'estimat i admirat director de l'Institut-Escola de la Generalitat, que va sobresortir pel seu tarannà, ciència i pedagogia.

Amb aquest article els autors volem reivindicar la seva personalitat polifacètica, la seva tasca professional, la seva ciència recreativa i l'actualitat de l'ideari pedagògic renovador, que en aquests moments de canvis i replantejaments són ben vigents en el món de l'educació.

(*) Llicenciat en Ciències Biològiques per la Universitat Autònoma de Barcelona. Documentalista. Membre de I'Institut d'Estudis Penedesencs. Ha publicat diversos articles i llibres sobre científics del Penedès. Adreça electrònica: jbaltam@gmail.com

${ }^{(* *}$ Doctor en Pedagogia i Màster en Assessorament Psicopedagògic, ambdós per la Universitat de Barcelona. Psicopedagog. Membre de la Societat d'Història de l'Educació dels Països de Llengua Catalana, filial de I'Institut d'Estudis Catalans. Soci de la secció catalana del PEN Club International. Per consultar la seva obra escrita, i d'altres activitats, entrar a la web: salvadordomenech.com Adreça electrònica: salvadordomenech@gmail.com 


\section{Com un científic esdevé referent i paradigma de la formació re- novadora}

Nascut a Vilafranca del Penedès (21/06/1879) i mort a Barcelona (20/04/1938), Josep Estalella inicià la seva activitat docent per no poder viure de la recerca científica, que és el que a ell li agradava. El 1902 es doctorà amb La trascendencia de la materia para los Rayos $X$ y su aplicación, tesi que obtingué la qualificació d'excel.lent a la Universitat de Madrid. Aquest rigorós estudi li comportà ser un dels pioners en la recerca dels raigs $X$, descoberts set anys abans pel físic alemany Wilhem Conrad Röntgen.

El juny de 1905 es va casar amb Joana Ayxelà i Mas i quatre mesos abans havia obtingut la càtedra de Física i Química a I'Institut de Girona ${ }^{1}$. El matrimoni s'hi desplaçà al setembre per tal de començar el curs escolar. L'estada com a catedràtic s'allargà catorze anys, durant els quals es va formar el corpus metodològic i didàctic del professor actiu i modernitzador. Allà tingué com a companys a personalitats rellevants i erudites com els doctors Rafel Ballester (Geografia i Història) i Manuel Cazurro (Ciències Naturals, per bé que llavors aquesta matèria se l'anomenava Història Natural), amb els quals segur que hi va haver una interacció enriquidora en l'àmbit professional.

Amb el seu esperit inquiet aplicà la seva màxima Quan facis alguna cosa, fes-la com si en allò t'hi anés la vida. D'aquesta manera reconvertí la seva matèria en una formació viva, tot el contrari del que s'aplicava en altres centres: anquilosament metodològic de lliçons magistrals en aules estàtiques. Va aconseguir que les seves sessions fossin pràctiques i experimentals, buscant el protagonisme de l'alumnat, incorporant les sortides i excursions a la programació, tant a la natura com als obradors i fàbriques de la ciutat.

La mort de la seva muller, el juliol de 1916, significà un gran trasbals emocional i familiar. Va haver de deixar la seva filla i fill petits amb els avis, a Vilafranca. La filla gran, Maria, restà amb el seu pare, continuant estudiant a l'institut. Més tard, quan estava a Madrid, també amb la Maria, vingué una altra batzegada sentimental: la mort, el gener de 1920, de Llúcia Vallet de Montano Nazareu, professora de Matemàtiques i directora de l'Institut de Girona, amb la qual estava promès.

Com que era una persona amb inquietuds, de reconegut prestigi acadèmic i de divulgador de la ciència en llibres i publicacions vàries, no deixà de perdre l'oportunitat d'incorporar-se al claustre de I'Instituto-Escuela, creat un any abans, el 1918, per un decret del ministre liberal Santiago Alba com assaig pedagògic. La seva posada en funcionament va representar la primera i més gran alenada d'aire fresc i de justícia social a l'ensenyança oficial. Es va oferir una educació comuna, coeducadora i generalitzada per a tothom, que trencà amb els compartiments separats de Primària i Secundària. La creació i organització va recaure en la Junta para la Ampliación de Estudios, entitat creada el 1907, i inspirada per la Institución Libre de Enseñanza fundada el 29 d'octubre de 1876 i encapçalada per Francisco Giner de los Ríos.

(1) Fins poc abans de la Segona República espanyola, excepte a Madrid, a l'Estat espanyol només hi havia un institut per província. Era una manera indigna d'uniformisme, ja que des del centralisme ancestral no es tenia en compte la població $i$ altres variables de les restants ciutats. 
Josep Estalella s'hi va sentir com a peix a l'aigua. Havia aconseguit trobar un lloc on, de manera collectiva, s'aspirava a trencar els procediments de l'escola tradicional, contra la magnificació del llibre de text, la instrucció, els exàmens i la falsa disciplina. Ell procurava vitalitzar la classe amb la finalitat que l'alumnat en fos el protagonista directe, a força de planificar i preparar cadascuna de les sessions de la matèria a desenvolupar, i l'alumnat anava confeccionant en la seva llibreta el seu llibre. Una vegada un company li va comentar que havia sortit de la classe completament suat $\mathrm{i}$ el doctor Estalella li va respondre amb la seva ironia plena de sentit comú renovador:

Vostè no ha de suar gens, és l'alumne qui ha de suar; vostè el que ha de fer és orientar els alumnes perquè treballin i suïn ells. (Entrevista personal al seu fill, Tomàs Estalella, el setembre de 1979)

Els seus companys li van reconèixer la seva vàlua quan va ser escollit director per al curs escolar 1921-22, tot i que només va poder exercir el càrrec durant el primer trimestre. La raó fou la mort del pare. Un altre sotrac que va precipitar que tornés a Catalunya, el més a prop de Vilafranca; cosa que va aconseguir fent una permuta de la plaça que tenia en propietat a Girona amb la del catedràtic gironí senyor Camps, de I'Institut de Tarragona. Aquest fet comportà una altra etapa més lligada al seu estimat Penedès. Durant aquests anys es va accentuar el lligam amb la seva vila natal i la seva gent, tot aportant els seus coneixements tècnics i humanístics en un munt d'iniciatives culturals, socials... El Penedès, indirectament, va modelar la seva idiosincràsia. Unes paraules escaients de la seva amiga, convilatana i companya de feina Anna Maria de Saavedra:

Els que l'havíem acompanyat tantes vegades per terres del Penedès i de Tarragona, recorden el seu incansable descobrint. En un món que era solament informe i amable sorgien profusament centres d'atenció apassionant. Detalls de paisatge, de fauna i flora, d'arqueologia, de geologia, de costums del país, de maneres d'anomenar. I ens transmetia amb la cosa descoberta, l'amor d'ella i de l'acte de descobrir-la. (De Saavedra, 1979, p. 57)

Ell haguera volgut abans portar a casa nostra l'experiència de l'Instituto-Escuela, però la Dictadura del general Primo de Rivera ho va impedir suprimint la Mancomunitat de Catalunya. La seva estada a Tarragona va comportar una època de maduració, reflexió i planificació vers un futur més afavoridor. Les sessions de classe continuaren sent pràctiques, enfocades amb el propòsit d'apropar la ciència a la realitat i d'accentuar els recursos de l'entorn en l'alumnat perquè copsessin millor les teories apreses. I fent referència al material científic, és il.lustrativa la resposta que donà al pare d'un alumne que anava a examinar-se per lliure a Tarragona, en preguntar-li, tot preocupat, com s'ho faria el seu fill de cinquè curs per estudiar la Física sense disposar dels aparells apropiats, ja que vivien en un poble de la rodalia:

Però com? És que al seu poble no hi ha politges en els pous, els paletes no tenen plomades, i els fusters no tenen nivells ni cargols, ni tenen malls els ferrers, ni rodes els carros, ni termòmetre els metges, ni hi ha campanes a l'església, ni timbres ni llum elèctrica, ni motors elèctrics, ni màquines de vapor, ni salts d'aigua, ni cap piano ni tambor o algun instrument de música...? (Cardús, 1979, p. 11-12)

Cap al final de la Dictadura, quan la presidia el general Berenguer, a poc a poc s'anà normalitzant la vida cultural i escolar del país. Mostra de la qual és el retorn de Manuel Ainaud al capdavant de l'Assessoria Tècnica de la Comissió de Cultura a començaments de 1930, havent estat destituït d'una manera ignominiosa el setembre de 1925. 
L'esclat regenerador va venir amb la proclamació de la Segona República el 14 d'abril de 1931. A escala estatal el ministre tortosí Marcel.lí Domingo, des del Ministeri d'Instrucció Pública (MIP), Iluità per transformar la situació deplorable de l'ensenyament públic; ja fos pedagògicament, de construcció d'edificis, de la ràtio d'alumnat per aula, de les seves condicions de seguretat, etc.

Des de la Generalitat de Catalunya es tenia ben present que el model a seguir a l'ensenyament primari era el que es portava a terme als Grups Escolars del Patronat i a les escoles municipals de l'Ajuntament de Barcelona, amb directors tan eficients com Rosa Sensat, Fèlix Martí i Alpera, Dolors Batlle, Llorenç Cabós, Anna Rubiés, i Llorenç Jou i Olió. Era en l'ensenyament secundari on s'havia de centrar els esforços.

La Conselleria de Cultura (que incloïa Educació), comandada per l'intel-lectual Bonaventura Gassol, va crear el Consell de Cultura per tal d'articular el teixit cultural del país, amb vint-i-dos consellers de la talla de Jaume Serra i Húnter, Rafel Campalans, Manuel Ainaud, Alexandre Galí, Joaquim Folch i Torres... Va ser la ponència d'Ensenyament Secundari comandada pel doctor Estalella i amb la collaboració de personalitats de la categoria de Joaquim Xirau, Pompeu Fabra, Jesús Bellido i Joaquim Balcells, la que estructurà el corpus pedagògic de I'Institut-Escola del Parc de la Ciutadella que va obrir les portes el 3 de febrer de 1932, a l'edifici de l'antic Palau del Governador i del que a l'Exposició Universal de 1888 va acollir el Palau Reial. Això sí, amb estreta connexió amb l'ensenyança primària establerta a Barcelona pel Patronat Escolar. La Generalitat li va posar el seu nom i l'Estat el va batejar com a Francisco Giner de los Ríos, encara que popularment se li deia Institut-Escola del Parc.

\section{L'Institut-Escola de la Generalitat}

Parlar de l'Institut-Escola de la Generalitat és parlar del doctor Josep Estalella i escriure sobre ell és fer-ho sobre la seva obra magna, tan anhelada de veure-la néixer després del seu pas per l'Instituto-Escuela de Madrid. Això era així. No en va fou ell qui escollí personalment els catedràtics del país i el millor de la darrera fornada de llicenciats en les branques de Ciències i Lletres. Respecte als darrers, volia que no tinguessin experiència escolar per aconseguir un millor acoblament a l'ideari del centre i del seu director, que venia a ser el mateix. Alguns membres del claustre que van esdevenir personalitats en les seves branques: Ramon Aramon, Josep Maria Calsamiglia, Guillem Díaz i Plaja, Joan Mascaró, Carme Serrallonga, Lluís Solé i Sabarís, Jaume Vicens i Vives...

Com que un dels importants objectius en la creació de l'Institut-Escola de la Generalitat era el de ser planter docent per als futurs centres que s'anessin creant, aquest aspecte es va fer realitat amb la posta en funcionament de I'I-E Pi i Margall, el de l'Eixample, i de l'Ausiàs March, a Sarrià. Malauradament, amb la inestabilitat política (bienni negre a Madrid i l'esclat de la Guerra Civil) i la curta durada de la República, no es van poder portar a terme més projectes similars a Barcelona i a altres ciutats. L'I-E Manuel Bartolomé Cossío es va inaugurar l'octubre de 1936, en plena efervescència del Consell de l'Escola Unificada (CENU), per iniciativa de la Comissió de Cultura de l'Ajuntament de Sabadell. Tot s'acabà el 26 de gener del 1939. 
En l'àmbit de claustre i, a escala docent estrictament, el doctor Estalella no era primus inter pares. Cap membre del professorat posava en qüestió la seva ascendència. Tenia un projecte formador de país i va demostrar en tot moment la seva ferma determinació d'acomplir amb un ensenyament humanístic, el més integral i interdisciplinari que va ser possible. Així com posar l'accent en què totes les matèries del currículum tinguessin un valor pedagògic similar, que cap sobresortís en excés a les altres.

El Pla d'Estudis era cíclic. És a dir, cada any s'estudiaven les mateixes matèries amb el benentès que cada curs comportava un nivell més avançat de contingut i complexitat; aquest fet permetia un desplegament d'eficàcia curricular vers la comprensió de l'alumnat al llarg del batxillerat. A més, cada disciplina que ho permetia era complementada amb treballs pràctics, experiments al laboratori; ús i estudi a la biblioteca; sortides per la ciutat i visites a obradors, museus, exposicions...; excursions per les rodalies de la ciutat i per poblacions i indrets de Catalunya, País Valencià, les Illes Balears i l'Estat espanyol. Sempre que el Iloc s'esqueia, s'aprofitava per completar coneixements de botànica, geologia, geografia, llengua, història, dibuix...

La pedagogia de l'Institut-Escola que ell va saber imprimir, d'una manera indirecta feia que cada noi i cada noia se sentissin especials; en cap cas amb faisó de superioritat ni de competitivitat entre ells. Va lligar l'aspecte emocional dins el currículum ocult. D'aquesta manera l'alumnat tingué més bona autoestima i, per tant, s'aconseguí que fossin capaços d'assumir els reptes educatius vivint-los com a propis, amb il.lusió, compromís i lliurament.

La seva estratègia era que l'alumnat arribés al coneixement mitjançant la pràctica i el raonament comprensiu. Res de memorització i d'exàmens tradicionals. Era fomentar el pensament crític positiu. Potenciar la resolució de qüestions complexes fent servir la creativitat, la flexibilitat de caràcter, la iniciativa pedagògica (afermant les aptituds i possibilitats pròpies) i la col-laboració amb els companys i companyes del grup-classe, els quals rebien els noms de muntanyes i poblacions de l'àmbit dels Països Catalans (Formentor, Montblanc, Montnegre, Peníscola, Puigmal...).

Al contrari dels altres tres Institut-Escola catalans, per assenyalar l'acabament de les classes no sonava cap sirena ni timbre. Normalment era el mateix doctor Estalella el que passava per les aules assenyalant l'estona d'esbarjo o I'hora de sortida, i d'aquesta manera ho aprofitava per anar supervisant les dinàmiques de classe; si el director no hi era o no podia, era el professor de guàrdia - un altre factor innovador al batxillerat català d'aleshores, al costat del càrrec de tutor- l'encarregat de fer-ho. A l'acabament del pati, amb un avís del director ja n'hi havia prou perquè nois i noies anessin a les classes ordenadament, sense haver de fer files. Al doctor Estalella també li agradava saludar personalment l'alumnat a l'hora d'entrar als matins i les tardes. Hi pot haver un millor exemple de sentir-se seu una obra col-lectiva?

Podríem definir què era l'Institut-Escola aportant definicions de persones que el van conèixer bé, com l'Alexandre Galí. O llegir els editorials i pàgines dels vint-i-dos números del butlletí Institut=Escola i dels quatre de la revista Escola editada per I'alumnat. Hem cregut millor, però, fer-ho amb una definició d'una de les seves més brillants alumnes, la Maria Aurèlia Capmany, del Grup Miramar: 


\begin{abstract}
Tota la pedagogia de l'Institut-Escola era una lluita constant contra la lliçó apresa, contra l'acumulació de dades memoritzades, contra els esquemes prefabricats, contra la comèdia preestablerta d'Examinador-Examinat, amb preguntes i respostes d'un catecisme escolar momificat. Tot havia de ser fet i refet en el taller, en el laboratori de l'aula, tot havia de derivar de la descoberta meravellosa, és a dir, del coneixement. Tant si es tractava de matemàtica, de biologia, de química, de poesia, de novellla, d'història, tot havia de ser pensat de nou, descobert de nou, com si el món s'anés construint a mesura que nosaltres vivíem. I viure era, com per Cusano un entrar més i més en el coneixement, és a dir, en la felicitat. (Capmany, juliol 1979, p. 29)
\end{abstract}

No podem acabar aquest apartat sense parlar de l'Angeleta Ferrer i Sensat. A més de ser la mà dreta del doctor Estalella, I'Angeleta exercia la coordinació entre l'etapa d'ensenyament primari i la d'ensenyament secundari, segons emanava de les disposicions del Règim Intern. A la pràctica també desenvolupava la funció de sotsdirectora, no només per la confiança que el doctor Estalella li dipositava, sinó per les seves excepcionals qualitats humanes i professionals vers l'alumnat. L'Angeleta Ferrer estava totalment identificada amb la manera de ser i fer d'ell, al qual l'admirava com a persona, com a científic i com a director. Tenia el do de la ubiqüitat: sempre estava quan se la necessitava. Les seves qualitats d'empatia i dinamisme la feien indispensable a l'hora d'organitzar, supervisar o d'implicar-se en bona part de les activitats lúdiques i d'horari no lectiu: rítmica, coral, teatre, pràctica d'esports, sessions de cuina, treballs de fusteria, de cistelleria, estades a Can Surell...

\title{
L'ideari del doctor Josep Estalella a través de les seves dites
}

Pels qui hem fet recerca sobre la vida i obra del doctor Estalella sabem fefaentment que és un dels grans savis que ha tingut el país. Molt conegut, de manera especial, dins el camp de la Història de l'Educació, de l'antic alumnat i la seva òrbita socialfamiliar, d'una part del cercle intel.lectual, i, com no podia ser d'altra manera, de la ciutadania de la seva població natal, Vilafranca del Penedès. Així doncs, en general, és una personalitat no prou reconeguda fora del món acadèmic educatiu.

Si ets docent, tens alumnat, però no tot el professorat pot tenir deixebles. Els qui van gaudir de la formació del doctor Estalella a l'Institut de Girona, al de Tarragona o a l'Institut-Escola de la Generalitat, han recordat per sempre el seu mestratge. Per llei de vida són ben pocs els que encara viuen, si bé el seu esperit resta dins seu; són els de l'etapa republicana. El seu procedir ha estat, d'una manera o altra, condicionat pel vitalisme i lliurament que el seu Mestre, amb majúscules, va saber inculcar en ells. Amb respecte i harmonia.

Més que parlar del seu ideari pedagògic a l'àmbit teòric, de les seves qualitats didàctiques, metodològiques, directives, d'interacció..., ens ha semblat que era més interessant verbalitzar la seva pràctica aplegant les seves dites, sentències, raonaments, reflexions... (recollides pels deixebles) per copsar-hi millor l'excel-lència professional i humana.

No hi són totes, òbviament, algunes ja les hem avançat, però les sentències que venen a continuació són excel.lents, si bé voldríem destacar les tres primeres, per l'essència formativa que transmeten.

- M'he proposat fer homes bons, si a més són forts, millor, i si a més resulten savis, millor encara (En el quarantè aniversari de la fundació de l'Institut-Escola 1932-1972, 1972, p. 31). Una vertadera declaració de principis que resta 
emmarcada en l'actual Institut Verdaguer, al Parc de la Ciutadella. Afirmació d'un humanista que va practicar per implementar un ensenyament el més integral possible. I per sobre de tot, educar persones, ciutadans.

- No calen plans, programes, mètodes, sinó mestres, mestres, mestres (ibídem, 33). El factor humà docent és el que va imprimir personalitat a la formació donada. Per alguna cosa era educar en valors.

- Aquesta és la clau de tot: l'amor a les coses com a promotor del seu coneixement; el coneixement de les coses com a causa de fer-les estimables (ibídem, 26). Professorat i alumnat van saber fer la seva tasca amb amor, però el marc idoni hi va contribuir molt. Si les escoles tradicionals compartimentaven el saber en parcel-les, ell va procurar en tot moment que el cos de professorat miressin més enllà del temari i tinguessin un enfocament interdisciplinari, el més vivencialment i actiu possible vers l'alumnat. A ell quan li preguntaven què feien els nois i noies a l'Institut-Escola ell els hi contestava: Aquí vénen a jugar $i$, de tant en tant, estudien.

- Dirigida a l'alumnat: Procureu que els que us rodegin estiguin tan bé com sigui possible. Quan tothom obeeixi aquest principi tothom estarà tan bé com sigui possible (ibídem, 33). Un principi infal-lible per obtenir una bona estabilitat emocional, personal i relacional.

La seva personalitat traspuava a totes hores i a tots els racons de l'edifici. Tenia do de paraula i sabia argumentar el que captava en les seves observacions quotidianes, esdevenint petites, però grans lliçons de civisme. En un dels seus llibres de poemes i records, l'exalumna Emília Quer i Búngeler explicita com d'una manera espontània en Josep Estalella els anava modelant:

El doctor Estalella tenia una gran capacitat per fer-se entendre pels seus deixebles i no desaprofitava cap ocasió per donar lliçons com aquell qui juga.

Recordo un dia que va entrar durant la classe al grup Montseny on jo anava, es va asseure damunt la meva taula i em digué:

-Sentarse en la mesa es gran grosería; sentarse a la mesa la cosa varía.

A la seva manera em va fer classe d'urbanitat i de gramàtica. No ho he oblidat mai més. (Quer i Büngeler, 2005, p. 81-82)

Avisava amb exemples, perquè te' $n$ recordessis a l'àmbit de comportament, d'urbanitat. A vegades es posava al costat d'un/a alumne i li deia:

Caram, tu trobes que s'assemblen aquestes sabates? (Domènech i Domènech, 2009, p. 152)

La comparació feia copsar que el calçat estava brut i aconseguia que l'endemà l'alumne anés amb sabates lluents.

$O$ bé amb poques paraules ben contextualitzades podia reconduir un fet que s'havia produït canalitzant-ho amb un exemple o comparació enginyosa. Com en la definició de brutícia, que va deixar al grup-classe bocabadat:

La brutícia és solament una cosa fora de lloc; per exemple, aquesta taula amb el paper està bruta, però si el paper el posem a la paperera, tot està bé, i si tu, noi, portessis el jersei amb una llàntia 
d'oli, aniries molt brut, però si el mateix oli estigués en un setrill, no passa res, tot està bé. (Ibídem, p. 155)

Intentava que l'alumnat es replantegés la seva possible actuació anòmala vers els principis de I'Institut-Escola, que reflexionés sobre el que era el més adequat. Volia i valorava l'autocorrecció, el domini d'un mateix per sobre de tot. La seva intervenció acostumava a ser moltes vegades uns comentaris llançats a l'aire. En Joan Bosch, del Grup Cadí explica la següent anècdota:

Una de les nostres escapades amb en Doreste i l'Argimón anàrem a voltar entorn del Desconsol, tot fumant unes cigarretes, tal volta facilitades per la Tarrida? Ja de retorn cap a I'Institut, encara amb la punta fumejant als dits ens vàrem trobar encarats amb el Dr. Estalella quan menys podíem esperar-ho. La sorpresa ens va envair i els colors ens pujaren a la cara. Ho esperava tot menys el que va dir el nostre director:

- Ja us heu guanyat els diners que val aquest tabac?

Podeu pensar com va ésser d'expressiu el nostre silenci!²

Una altra vegada, davant una noia -Anna Garcés- que es balancejava sobre la cadira de classe, el doctor Estalella, que passava per allà, com si no anés per a ella, va dir:

En aquesta classe hi ha una noia que no sap que s'han inventat unes cadires per gronxar-se, que se'n diuen Balancins... (ibídem)

I continuà caminant sense dir res més. Una amiga comentà que no s'havia gronxat més sobre cap cadira.

Explicació ben explícita de Núria Fusté. Quan el diàleg i el pacte passa per sobre de qualsevol càstig:

Un dia jugàvem a fet durant l'esbarjo. De sobte, creient que m'anaven a agafar, vaig fer un crit agut i llarg, que es devia sentir des de Montjuïc. Com per obra d'encantament va aparèixer davant meu el Dr. Estalella.

- Qui ha cridat?

Recordant la meva primera escola, i tement lo pitjor, vaig contestar amb un fil de veu.

- Jo.

- Tu ets la noia nova, la Núria, oi? Doncs, vine amb mi, que et vull contar una història.

I tot passant-me el seu braç per l'espatlla, vàrem anar caminant com si fóssim dos grans amics, sota el sol del matí d'hivern. Jo no me'n sabia avenir pensant en el clàssic càstig que m'hauria plogut a l'altra escola.

Tot passejant em va contar una llarga història d'Adam i Eva al paradís. No recordo per quin motiu sembla que Eva va fer un xiscle que li va travessar el moll dels ossos al pobre Adam que estava tan tranquil.

Adam al sentir el crit es va quedar de pedra i li va dir:

- Escolta noia, això no ho tornis a fer. El crit és una defensa de la dona, però creu-me, si n'abuses, cridaràs i ningú en farà cas.

(2) Recull de records escrits, fotografies i dibuixos d'exalumnes, aplegats en una capsa que se li va regalar a l'Angeleta Ferrer, a Can Sunyer del Palau (Castellví de Rosanes), el 31 de maig de 1974, en motiu de la seva jubilació. Sense numerar. Obra manuscrita i mecanografiada inèdita al públic. 
La història continuava, però com que des que el Dr. Estalella me la va explicar han passat alguns anys, no en recordo res més, és a dir, n'he guardat l'esperit de la rondalla, no els detalls; però sé que em va convèncer.

- I ara (va dir per acabar el Dr. Estalella) tu i jo farem un pacte. Tu em promets que no cridaràs mai més i jo accepto aquesta promesa. Però els pactes s'han de signar. Vine!

Em féu anar al seu despatx. Agafà un tros de guix i amb lletres molt grans va guixar a terra la seva signatura. Després em donà el guix.

- Ara signa tu.

Sota la seva signatura hi vaig escriure la meva. Fou un acte molt solemne.

- Bé, ara ja tén pots anar. Ja sé que mai més cridaràs en va.

Va tenir raó: mai més, per motius que hagi tingut, he xisclat. És més, crec que encara que volgués fer-ho expressament no en sabria.

Paraula de català (ibídem).

Al Palau del Governador hi havia uns principis col-lectius que donaven personalitat a I'Institut-Escola del Parc i, per tant, el doctor Estalella no veia amb bons ulls que hom es passés per alt la normativa, escrita, verbalitzada, o no. També hi ha manifestacions seves on accepta la relaxació en disciplina, com en el cas següent respecte a uns nois i noies que van preferir quedar-se al voltant de la masia de Can Surell en lloc de fer una sortida determinada:

També se'ls ha de deixar que s'esbravin una mica, sempre disciplina els cansa. (ibídem)

Can Surell era la Colònia Escolar pròpia que tenien al Montseny, i que el doctor Estalella valorava molt les estades que s'hi feien perquè s'hi reflectia la personalitat espontània de cada noi i cada noia.

Hi havia un ordre de comportament, però no el que tradicionalment s'anomena disciplina. La convivència basada en el respecte als altres i a les coses del comú feia que no hi hagués els casposos càstigs, ni físics ni verbals. En cap cas s'empraven mètodes coercitius, ni escarments ni humiliacions. Era un saber estar no imposat, sinó viscut, ben interioritzat. Cadascú acabava sabent què calia fer i el perquè.

La Modesta Oñate, com alumna del grup Cadí de I'Institut-Escola, parla amb propietat sobre l'ús que se'n feia del llibre de text. En l'àlbum recull d'escrits en homenatge a l'Angeleta Ferrer, ho reflecteix així:

\footnotetext{
Una cosa que va ésser, en un principi, motiu de crítica del nostre Institut per part d'altres institucions similars d'aquella època, fou la supressió del llibre de text. Sense llibres, com poden estudiar es demanaven. Es deia que preteníem substituir la correcció dels llibres de text per la imperfecció dels apunts, sense comprendre que, com deia el Dr. Estalella: Estudiar no consisteix a llegir, sinó a observar sobre l'objecte motiu d'estudi. El llibre, per a nosaltres, era, fonamentalment, un instrument de treball o de consulta bibliogràfica. Més tard, en els darrers cursos, ens ajudà a la sintetització dels coneixements adquirits. (ibídem)
}

Josep Estalella era una persona de principis (la humilitat és la veritat) i creia fermament en l'obra pedagògica renovadora, i revolucionària, que capitanejava. Respecte a la no aplicació dels exàmens com a mesura de valoració i avaluació, la Maria Aurèlia Capmany recorda l'opinió, clara i rotunda, que en tenia el director arran d'haver de fer la prova d'accés a la Universitat: 
Era poc temps abans del nostre ingrés a la Universitat. Els components dels grups Puigmal i Miramar sabíem que aviat ens hauríem de sotmetre a un examen. (...)

En el fons, estàvem nerviosos i sobretot n'estàvem perquè descobríem que els nostres professors se'n sentien més que nosaltres. L'únic que es mantenia serè era el doctor Estalella o almenys aquesta era la impressió que donava. A més, si algú es lamentava dient: "Aquests nois no han après a examinar-se". Ell contestava impassible:

- Naturalment que no n'han après. Com no han après a robar ni a mentir. Les coses mal fetes no s'han d'aprendre a fer. (En el quarantè..., 1972, p. 30)

Ell era catòlic, si bé en cap moment transmetia aquest sentiment en l'àmbit laboral. Però sí que emfatitzava l'espiritualitat i sensibilitat que tota obra ha de contenir, anant més enllà del materialisme. Espiritualitat i sensibilitat:

-I un Institut-Escola, com tota obra essencialment espiritual, no es fa pas amb ponderables, ans amb imponderables (Ibídem).

-Potser tota la pedagogia es podria reduir a aquesta fórmula: incrementar la sensibilitat de l'infant, sensibilitat física, sensibilitat intel·lectual, sensibilitat estètica, sensibilitat moral. Si la vida és el conjunt de relacions de l'individu amb el medi, aquestes relacions s'han d'incrementar si es vol incrementar la vida. (Ibídem, p. 32)

«A I'Institut-Escola ens preocupem més pel continent que pel contingut. Reconeixem que el coneixement, en si, no té cap valor, i només el té positiu, i només li'n dóna la qualitat de la persona que l'adquireix.» (Capmany, 1987, p. 124). Prioritzava les competències personals, familiars, socials, humanitzant l'educació.

\section{Cent anys de la Ciència Recreativa.... del Dr. Josep Estalella}

La continuada reedició del llibre que el doctor Josep Estalella va publicar el 1918 Ciencia recreativa. Enigmas y problemas. Observaciones y experiencias. Trabajos de habilidad y paciencia ${ }^{3}$ - quan estava a la ciutat de Girona com a professor de Física a I'Institut Vell, fins a hores d'ara, ens pot fer pensar que indiscutiblement la seva edició va ser un esdeveniment en el seu temps encara no superat en el camp de l'ensenyament didàctic, de les ciències físiques de forma preferent. També, aquest repetitiu recordatori de l'excel·lència de la figura del Dr. Josep Estalella envers el canvi de la metodologia de l'ensenyament en general a les aules catalanes durant el primer terç del segle $\mathrm{xx}$, gràcies especialment a la seva tasca directiva i docent a I'Institut-Escola de la Generalitat, ens pot fer prejutjar negativament l'ambient pedagògic i limitar-nos en la recerca dels antecedents de les persones i esdeveniments

(3) Ciencia recreativa. Enigmas y problemas. Observaciones y experiencias. Trabajos de habilidad y paciencia. Barcelona, Quinart y Pujolar, 4, 2 h., 512 pp., 802 figs., 23 cm. Es varen realitzar edicions posteriors: 1930 (Barcelona, Ed. G.G., 514 pp.); 1942 (2a ed., 514 pp., 23 cm.);1960 (5 a ed., Barcelona, Ed. G. Gili,

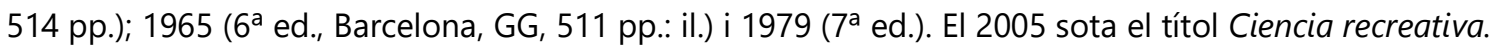
Libro segundo, Observaciones y experimentos: física, química, cuestiones de geografía e historia natural l'editorial Competium, Girona, va fer una edició preliminar commemorativa amb motiu de l'any internacional de la Física: 514 pp.: il.; 22 cm. El 2007 l'Ajuntament de Barcelona va promoure una edició facsímil de la $2^{a}$ ed. rev. (514 pp.: il.; $23 \mathrm{~cm}$.). Sota el títol Ciencia recreativa: facsímil y comentarios, el 2008, Competium (Girona, 734 pp.: il.: 23 cm.) i la Fundación Séneca, Agencia de Ciencia y Tecnología de la Región de Murcia (Girona, Imp. Pagès, 734 pp.: il.; 23 cm.) va realitzar cadascuna d'elles una edició. El 2009, el Collegi d'Enginyers Tècnics Industrials de Girona varen dur a terme una edició de l'obra sota el títol: Ciència recreativa: observacions i experiments: facsímil amb comentaris (497 pp.; il.; $23 \mathrm{~cm}$.). 
educatius que també van estimular d'una manera indirecta i directa l'edició d'aquest llibre. A vegades pot semblar que abans d'ell tot estava per fer, la qual cosa en absolut és certa, alhora que no li resta en absolut mèrit a l'obra en qüestió de què parlarem i al seu autor.

Tot i que a finals del segle XIX l'estudi de les ciències en general a l'Estat espanyol era prou millorable -el 1847 es va crear la Real Academia de Ciencias Exactas, Físicas y Naturales com a òrgan consultiu, i el 1857 la Facultad de Ciencias Exactas, Físicas y Naturales, amb uns programes prou endarrerits i una manca important d'esperit experimental entre el professorat- existia un nombre important de docents que des de l'àmbit acadèmic denunciaven aquest fet $\mathrm{i}$ actuaven de manera individualitzada en pro de capgirar aquesta situació mitjançant la divulgació de la ciència en general, l'edició de llibres o amb accions d'associacionisme científic per tal de sensibilitzar a la societat civil, i que aquesta al seu torn exigís a les autoritats governatives canvis en la política educativa de l'estat. Tasca que també realitzaven altres personatges des d'un vessant benefactor, pedagògic o bé lligat a uns interessos personals al món editorial de la divulgació tècnica i científica. Pel que fa als primers, per ser figures reconegudes com a impulsores d'aquest canvi, podem esmentar, entre altres, a Gumersindo Vicuña Lazcano (1840-1890), Manuel Rico Sinobas (1821-1898), José Rodríguez Carracido (1836-1928), Francisco de Paula Rojas Caballero-Infante (18321909), Venancio González Valledor (1805-1867), Juan Chavarri (¿-1877), José Echegaray Eizaguirre (1832-1916), i de manera prou destacada a Eduardo Lozano Ponce de León (1844-1927) ${ }^{4}$ per les seves implicacions personals amb el jove Josep Estalella quan aquest era estudiant universitari a la ciutat de Barcelona. Respecte als segons podrien ser personatges prou representatius el gran mecenes gironí Rafel Patxot i Jubert (1872-1964), I'editor Gustau Gili i Roig (1868-1945), els pedagogs Francisco Giner de los Ríos (1839-1915) i Manuel Bartolomé Cossío (1857-1935)5 , i I'editor i enginyer Josep Alcover i Sallent (1835-1894) ${ }^{6}$.

Des del món editorial cal recordar que a principis del segle xx a Barcelona l'editorial Sucesores de Manuel Soler comptava amb una col·lecció anomenada Manuales Soler que tenia com a finalitat «poner al alcance del público el pensamiento de grandes autores, por lo general españoles, vinculados a una línea progresista, con una clara vocación científica de sesgo divulgativo (física, química, médico-higiénica, agricultura, etc.... pequeños volúmenes de un tamaño de $11 \times 16$ centímetros), editados con cubiertas duras... contribuían a divulgar el libro de bolsillo en un intento de popularizar la cultura» (Vilafranca, I. i Vilanou, C., 2018, p. 153). El fons d'aquesta

(4) Mereix una menció especial aquest personatge per la seva interacció personal amb el Dr. Estalella. En molts aspectes va seguir els seus passos, ja que el Dr. Lozano també va ser professor d'institut abans de catedràtic a la Universitat de Barcelona (Cobos Bueno, 2007).

(5) Dues personalitats que estan molt relacionades amb la pràctica dels krausistes espanyols -doctrina defensada pel pensador alemany Karl Christian Friedrich Krause- que proclamava el contacte directe de l'alumne amb la natura, el laïcisme, l'antidogmatisme..., ja que el primer fou fundador de la Institución Libre Enseñanza (ILE) i el segon fou el seu successor.

(6) Aquest altre personatge és prou representatiu de tots aquests prohoms. Va estar uns dels enginyers més coneguts de la segona meitat del XIX gràcies a la seva tasca com a editor de la revista La Gaceta Industrial Económica y Científica Consagrada al Fomento de la Industria Nacional. La revista es va editar des del 1864 fins al 1891, informant de les principals novetats tècniques alhora que denunciava les deficiències industrials del país (Baltà i Moner, Jaume. Ciència i Tecnologia al Penedès. Passat, present i futur. Edita Heretat Baltà de Cela, 2017, p. 33-43). 
editorial va ser absorbit anys després per l'Editorial Gallarch que seguiria publicant els manuals sota el nom de Manuales Gallarch amb continguts de ciències, història, arts, oficis...

\section{Les influències pedagògiques d'Eduardo Lozano}

La figura pedagògica del catedràtic Eduardo Lozano ha estat força estudiada darrerament i podem afirmar certament que el seu magisteri a la Universitat de Barcelona - dins la secció d'estudis de Física i Química - va ser clau per fer possible anys més tard l'aparició de figures destacades dins els estudis de la Física catalana de principis del segle XX, com Eduard Fontserè i Riba (1870-1970), Josep Comas i Solà (18681937) i el mateix Josep Estalella i Graells. Tots ells deixebles, que van destacar de manera prou meritòria en els camps de la investigació i divulgació científica i també de la pedagogia. Fontserè va ser el pare de la moderna meteorologia catalana i Comas i Solà un gran divulgador i observador dels astres.

Eduardo Lozano fou un home que va néixer en una família benestant on la pedagogia i la formació acadèmica formava part de la seva vida -el seu pare era cirurgià i tots els seus germans van gaudir d'estudis universitaris: una mestra, un farmacèutic i tres metges - i professionalment va estar relacionat amb l'ensenyament de les ciències físiques. Des de la seva joventut va ser un home preocupat per la renovació pedagògica i la divulgació científica publicant nombrosos articles i llibres. Aquest interès pel millorament de l'educació civil i el coneixement científic de la societat en general el portà pels vols de 1872 a fundar la Sociedad de Profesores de Ciencias, entitat que sota la seva presidència publicaria la Revista de la Sociedad de Profesores de Ciencias, títol prou eloqüent de la voluntat de comunicar les idees de renovació pedagògica a un determinat escalafó acadèmic. Pels volts de 1893 va crear la Sociedad Española Protectora de la Ciencia que tenia com a principal finalitat ajudar els destacats joves universitaris amb recursos econòmics limitats. Sabem que va fundar la Sociedad de Amigos de la Educación Infantil amb la ferma voluntat que cap poble quedés sense escola primària, i que va presidir (1897?) alguns anys la Sociedad Barcelonesa de Amigos de la Instrucción.

Indubtablement, tot i la seva avançada edat, quan fou professor del jove Josep Estalella a la Facultat de Ciències Físico-Químiques de Barcelona, aquest hauria de veure's influenciat per les seves idees de renovació pedagògica i el valor de l'experimentació que defensava el mestre per fer arribar els conceptes físics a l'alumnat. No hem d'oblidar que eren anys on existien fets prou importants dirigits envers aquests canvis pedagògics i la introducció de l'experimentació científica: reorganització del Real Observatorio de Madrid, 1864; fundació de la Institución Libre de Enseñanza (ILE), 1876; naixement del Museo Pedagógico de Primera Enseñanza, 1882; posada en funcionament del Laboratorio Microbiológico Municipal de BarceIona, 1886-1887; creació, a instàncies de la ILE, de la Junta para la Ampliación de Estudios e Investigaciones Científicas (JAE), 1907, que tindria un paper clau en la renovació pedagògica i científica espanyola; fundació de la Escuela Superior de Magisterio, 1909; inauguració de la Residencia de Estudiantes i del Centro de Estudios Históricos, 1910; gestació de la Fundación Francisco Giner de los Ríos amb la finalitat de conservar i difondre el llegat històric de la Institución Libre de Enseñanza, 1915; i finalment, el 1918, va obrir les portes I'Instituto-Escuela de Madrid. 


\section{Abans de la Ciencia Recreativa... de Josep Estalella i Graells}

L'edició d'obres recreatives, o de joc, per explicar els coneixements matemàtics i físics ja fou un fet per part d'alguns autors en els segles XVII-XVIII a França i Anglaterra $^{7}$. Val a dir que a vegades aquests llibres també estaven molt relacionats amb els jocs de mans i la màgia. Ja en el segle XIX podem esmentar algunes obres de referència. Récréations physiques, 1861, d'A. Castillon, de l'editorial francesa Hachette i que el 1863 va ser traduït al castellà per l'impressor Mellado de Madrid. El 1881 va veure la llum Récréations scientifiques ${ }^{8}$, de Gaston Tissandier, de l'editorial Georges Masson, realitzant-se nombroses edicions d'aquesta publicació; el 1893 en va sortir la sisena. Les experiències que s'explicaven en aquest llibre, per la seva curiositat envers el gran públic lector de la premsa diària, eren prou divulgades a diferents capçaleres del moment, tot i que no s'esmentaven les referències de l'autoria. També cal destacar l'aparició, el 1891, de la primera edició d'una traducció al castellà de l'obra del professor francès Arthur Good -que signava amb el pseudònim de Tom Tit-, Ciencia Recreativa, de l'editorial Fuentes y Capdeville de Madrid. A l'índex d'aquest llibre es pot observar un centenar d'experiments al llarg de les seves 244 pàgines; en moltes ocasions anaven acompanyats de dibuixos que hi facilitaven la comprensió. Òbviament, aquestes obres tenien com a principal finalitat la popularització de la ciència en un moment en què la modernitat i la intel-lectualitat eren un dels principals reptes de la societat espanyola, al mateix temps que existia una important corrent de pensament en alguns estaments socials relacionats amb la pedagogia que apostava per un ensenyament laic, actiu i no memorístic; és a dir, lluny dels dogmes oficials en matèria religiosa, moral, política... i més proper al joc, a la llibertat de càtedra i a un aprenentatge personal experimental.

Caldria esperar uns quaranta anys des de la primera edició de Gaston Tissandier perquè arribés la publicació del llibre Recreaciones científicas ó la física y la química. Sin aparatos ni laboratorios y solo por los juegos de la infancia del Dr. Estalella. La seva primera edició va veure la llum el 1918 per l'editorial Gustavo Gili, especialitzada en obres científiques i tècniques, a la Impremta Moderna de Guinart i Pujolar. L'editorial era prou coneguda per Josep Estalella, amb la qual collaborava com a traductor des de feia anys i la impremta era en aquells moments una de les millors existents a Barcelona. La seva ràpida lectura i la visualització dels nombrosos gràfics que acompanyen les diferents experiències, amb 532 activitats, 802 dibuixos i 991 entrades explicatives al llarg de 499 planes, ens permet acostar-nos d'una manera prou fàcil a observar molts misteris de la ciència alhora que comprendre millor la natura. L'índex, en un primer moment, ens recorda el llibre de Tom $\operatorname{Tin}^{9}$, tot i que és prou més eloqüent la seva finalitat pel contingut. L'obra està dividida en tres llibres i cadascun d'ells compta amb diferents capítols. Així el primer llibre sota el nom d'Enigmas y problemas engloba tres apartats: I, Cuestiones de Aritmética; II, Cuestiones geométricas i III, Cuestiones varias. El II llibre, sota el títol d'Observaciones y experimentos, també té tres capítols: I, Cuestiones de Geografía e Historia Natural; II,

(7) Sablonnière, Catherine. «Les récréations scientifiques: diffusion et succès de l'œuvre de vulgarisation de Gaston Tissandier en Espagne à la fin du XIX siècle». Amnis. Revue d'études des sociétés contemporaines Europe/Amériques, 14/2015 (En línia, data consulta 28 d'agost de 2019).

(8) El 2010 Editorial Maxtor va fer un edició facsímil del Ilibre.

(9) El Dr. Estalella esmenta l'obra referenciada a la seva Bibliografia a Ciencia Recreativa... 
Química i III, Física. El III llibre, i darrer, està dedicat a Trabajos de habilidad y paciencia amb dos capítols: I, Dibujos, fotografías y reproducciones análogas i el II a Construcciones de papel. En definitiva, és una obra madura fruit d'anys d'experiència com a professor ${ }^{10} \mathrm{i}$ molt superior a qualsevol de les publicades fins aquells moments pels recursos didàctics i metodològics, capacitat de treball recopilatori i innovador en les experiències descrites per l'autor. Tot el llibre és un bon exemple del que es pot arribar a avançar pel que fa a la comprensió de qüestions d'aritmètica, geometria, física, química, dibuix, fotografia, construccions de paper, geografia, d'història natural... mitjançant les nombroses i diverses observacions $i$ experiències presentades d'una manera fàcil i a manera de joc. En aquets punt, cal esmentar l'article del professor Callís i Franco «Les experiències de Ciència Recreativa, del Dr. Josep Estalella, i Aprenentatge matemàtic» (2007), on fa una detallada anàlisi del contingut del Ilibre.

Tal com el mateix autor esmenta en el pròleg, aquest llibre volia fer arribar a tots els joves estudiants $\mathrm{i}$ també adults amb curiositat per la ciència:

\begin{abstract}
Frivolidades, experimentos vistosos, curiosidades, paradojas, entretenimientos, correrías por diversos campos científicos, bordeándolos mejor que atravesándolos y no deteniéndose en ninguno: he aquí lo que comprende este volumen con la común denominación de Ciencia Recreativa. Nadie busque en él la exposición de ideas trascendentes o la resolución de problemas de actualidad palpitante. No se escribió con tal fin.....». (Pròleg de Ciencia Recreativa..., $2^{\mathrm{a}}$ ed., Gustavo Gili Editor, 1930)
\end{abstract}

En definitiva, era un llibre fruit de l'experiència pedagògica que ja tenia el Dr. Estalella després d'uns quants anys de ser catedràtic a l'Institut Vell de Girona, era una eina pedagògica que el professorat podia utilitzar a manera de guia, però també era un autoguiat per a tots aquells que tinguessin curiositat per les ciències en general. També hem de dir que no era, com el mateix autor esmenta, «absolutamente original» (Pròleg de Ciencia Recreativa), ja que en la bibliografia cita molts llibres referencials, entre els quals es troba el de Gaston Tissandier, però també defensa que tampoc és una obra recopilatòria: «abundan en este libro los experimentos originales, y además de referirse a los objetos de uso corrientes en obras similares, se tiene en cuenta la difusión alcanzada en nuestros tiempos por aparatos tales como el cinematógrafo, o como la lámpara eléctrica....» (Pròleg de Ciencia Recreativa...).

L'obra, per si mateixa, ens mostra la gran preocupació i capacitat que tenia el Dr. Estalella per l'educació dels joves i la seva gran tasca en pro d'aquest ensenyament

(10) Un cop situat a Girona va començar a impartir classes modificant la manera d'impartir-les, utilitzant aparells didàctics --va rescatar una esfera copernicana a instàncies del Dr. Eduard Fontseré (1870-1970) per explicar el moviment dels astres construïda a mitjans del XIX-, fent sortides a la natura amb els estudiants; fins i tot durant el període 1906-1908 va fer de bibliotecari a l'institut de la ciutat. Bon exemple d'aquesta experimentació pràctica educativa va ser la represa de l'activitat de l'estació meteorològica de l'institut, sota la seva direcció, amb finalitats pedagògiques del tot empíriques i més participatives per a l'alumnat, publicant-se les dades a la capçalera gironina La Lucha. Diario de avisos y noticias, però fent al.lusió als alumnes que s'encarregaven de la recollida de la informació. A banda, durant aquests anys a Girona va publicar diversos llibres de caire didàctic com: Colección de targetas para facilitar el estudio de la Química (Barcelona, Ed. G. Gili, 12º, 23 p., 13 fig., i 328 targetes). El 1914 es va realitzar una segona edició, Ejercicios prácticos de Física elemental (Barcelona, Impr. Moderna de Guinart i Pujolar, 8a, VIII+147pp.); 38 fig. Prácticas de Física. Iniciación en el estudio experimental de la Física (Barcelona, Ed. G. Gili, 8a, 146 pp., 26 figs). Es varen fer edicions posteriors: 1926 ( $2^{a}$ ed., ref. i ampl., 146 pp., 19 cm.); i 1936 (3a ed., 146 pp., 19 cm.). (Baltà i Moner, 2017, p. 89 i p. 95). 
actiu que defensarà al llarg de la seva vida, ja sigui com a professor (Institut de Girona, Instituto-Escuela de Madrid, Institut de Tarragona, Institut-Escola de la Generalitat) o bé com actiu articulista a les revistes Notas de Enseñanza, Revista de Segunda Enseñanza. A I'Institut-Escola de la Generalitat de Catalunya, com a director marcarà el model a seguir: coeducació, l'ús del català com a llengua bàsica d'estudi i relació, el laïcisme, les classes a l'aire lliure, l'educació renovadora... En definitiva, una manera de formar que no ha perdut en absolut vigència a pesar del pas del temps i la revolució tecnològica. Tot al contrari, ens mostra que el Dr. Estalella feia servir la curiositat com a motivació per portar al dia a dia la relació ensenyamentaprenentatge com a recurs pedagògic alhora que feia servir com a recurs didàctic els diferents elements de la ciència recreativa.

No podem deixar de recordar que el 1919, un any després de publicar el seu Ilibre de Recreaciones Científicas..., el Dr. Estalella va estar proposat com a professor de I'Instituto-Escuela de Madrid per la Junta para Ampliación de Estudios e Investigaciones Científicas ${ }^{11}$ per tal d'integrar-se i tirar endavant el projecte de la Càtedra de la secció de Ciències Físico-Químiques al costat d'altres professors ${ }^{12}$, que portaven altres seccions i recordats a hores d'ara com grans personatges de la renovació literària i de la ciència espanyola de la categoria de Ramón Menéndez Pidal (18691968), Julio Rey Pastor (1888-1944), Ignacio Bolívar (1850-1944)..., la qual cosa ens permet entendre encara més la vàlua de la seva persona com a pedagog. Solament els catedràtics d'institut o d'escoles tècniques en podien ser. Encara que el Ministeri d'Instrucció Pública els designava, la Junta -presidida per l'eminent científic Santiago Ramón y Cajal- era qui presentava els candidats.

\section{I cent anys desprès de la Ciencia Recreativa...}

Aquest llibre va ser publicat amb la finalitat de ser una eina didàctica. A hores d'ara els especialistes en pedagogia i recursos didàctics escriuen àmplies referències o es realitza exposicions commemoratives del centenari. És un fet que ens mostra, tot i la revolució tecnològica, que encara guarda l'essència de quan es va manufacturar i

(11) Ens consta l'existència de correspondència entre el llavors rector de la Universitat Central de Madrid, José Rodríguez Carracido (1856-1928) on s'esmenta l'interès de la Junta -ell era vocal de la mateixapara Ampliación de Estudios per la seva persona, per tal que s'incorporés com a professor a l'Instituto Escuela. Aquesta correspondència es conserva en l'Arxiu del Ministeri de Educación, Cultura y Deportes, a Alcalà de Henares, Madrid, l'apartat Expedients personals de Catedràtics: Estalella $5682-10$ (Baltà i Moner, J., «El Dr. Josep Estalella i Graells (1879-1938) a través dels seus epistolaris», Revista del Penedès, de l'Institut d'Estudis Penedesencs, 2017).

(12) La recerca de bons docents per part de la Junta amb la finalitat d'incorporar-los a I'I-E fou extraordinària. La llista de professorat que hi va exercir és força llarga i la gran majoria eren persones de talent, ja demostrat en aquells moments o que van brillar anys després a l'exili. Un dels professors que també es va relacionar amb I'Instituto-Escuela va ser el Dr. Edmundo Lozano Cuevas (1856-1919), polifacètic, aventurer i amic personal de Francisco Giner de los Ríos; notable pedagog que ja fou professor de la Institución Libre de Enseñanza formant part del professorat de Física i Química fins a 1890 i posteriorment es va incorporar de nou el 1906 al Museo Pedagógico Nacional, on s'encarregà d'impartir els cursos pràctics de Química, creant en el mateix un «laboratorio-taller, con el objetivo de que sirviese de modelo para la enseñanza de la física y la química en la escuela...». També publicà nombrosos articles i llibres on mostrava una metodologia didàctica activa en la línia de Ciencia Recreativa... Vegeu: Monzón Pinilla, C. i Usón Jaeger, A. (1997) «Propuestas didácticas innovadoras para la enseñanza de las ciencias físicas y naturales en el primer tercio del siglo XX en la escuela primaria española», Revista Complutense de Educación, vol.8, núm. 1, p. 271-289. 
que l'esperit del Dr. Estalella hi és prou viu. Després de 1918 es van editar altres obres de caràcter recreatiu, entre els quals cal destacar Las ciencias físico-naturales en la escuela, 1922, de Joaquim Pla i Cargol.

Parlar dels articles i llibres sobre Ciencia Recreativa.... és en essència parlar del seu autor i de la seva obra pedagògica, dels seus recursos didàctics i de llur finalitat en escriure'l: promoure el pensament d'una manera autònoma, facilitar la capacitat de formular-se preguntes, relacionar diferents coneixements i donar una resposta definida en cada cas concret. A tall d'exemple, el professor de Didàctica de les Matemàtiques a la Universitat de Girona, Josep Callís i Franco, en el seu article «Les experiències de Ciència Recreativa, del Dr. Josep Estalella, i aprenentatge matemàtic» (2007), analitza el contingut, coherència, plantejaments i metodologia del llibre; conclou que té una «metodologia activa i innovadora que fóra bo saber aprofitar a les nostres aules». També el catedràtic Àngel Alsina i la professora Núria Planas, en la seva obra Matemáticas Inclusiva. Propuesta para una educación matemática accesible (2008), volen donar veu, de nou, al Dr. Estalella per tal de plantejar activitats pedagògiques que facilitin l'interès dels joves estudiants per les matemàtiques a través d'un pensament crític, la manipulació, el joc i l'atenció a la diversitat. El físic Rafael García-Molina, de la Universitat de Múrcia, en el seu article Ciencia recreativa: un recurso didáctico para enseñar deleitando, de 2011, ens explica la història i la importància de la ciència recreativa com a eina docent per tal de superar la poca motivació de l'alumnat per aprendre i dels docents per poder ensenyar, i de la necessitat que aquests darrers tinguin els suficients recursos didàctics per fer participar els estudiants, recordant la vàlua de la ciència recreativa en el context educatiu ja existent en alguns plans d'estudis de secundària i universitaris.

A l'àmbit de la recerca acadèmica, fer esment de la tesi doctoral d'Óscar Raúl Lozano Lucia titulada La Ciencia recreativa como herramienta para motivar y mejorar la adquisición de competencias argumentarias, presentada el 2012 a la Universitat de València, al Departament de Didàctica de les Ciències Experimentals i Socials. Explica la crisi que existeix a hores d'ara a l'ensenyament de les ciències experimentals, que es tradueix en menys alumnat d'aquestes especialitats i que molt possiblement la causa principal d'aquest fet es troba en la metodologia i didàctica de l'ensenyament de la ciència; per fer front a aquesta situació apunta a la introducció d'elements de ciència recreativa per tal d'afavorir l'adquisició d'arguments participatius millorant l'interès per la ciència.

\section{Conclusió i actualitat}

Les reedicions i publicacions facsímils de Ciencia Recreativa..., sempre lligades a actes commemoratius de caràcter científic o tècnic ens serveixen de recordatori, o són un homenatge a l'autor, per la seva aportació a la pedagogia catalana. Que encara se'n parli a hores d'ara, quan els ordinadors, telèfons mòbils i tauletes són presents en quasi totes les activitats dels més joves, té el seu mèrit. Ara bé, precisament pel perill d'individualització que comporta, és més necessari que mai l'educació activa i guiada per part del professor pedagog, procurant fer-los néixer la curiositat pel coneixement $\mathrm{i}$ aconseguir que copsin i interioritzin els entrellats de la ciència, de la natura i del conjunt de la cultura humana. I potenciant a l'alumnat llurs habilitats i 
aptituds per tal que siguin capaços d'emprar la innata capacitat d'aprendre, de pensar i deduir per si mateixos al llarg de la seva vida. Ciencia Recreativa... està més viva que mai.

Comptats docents que no han vingut del camp del Magisteri o de la Pedagogia han pogut excel-lir com a renovadors pedagògics. I menys encara dels àmbits de l'educació Secundària i Primària alhora, aquest darrer per derivada. Històricament res és igual. Ara bé, la pedagogia del doctor Josep Estalella continua sent ben present no només en els docents, especialistes i estudiosos de la Història de l'Educació, sinó en la part de la ciutadania interessada per aquella experiència innovadora que va gestar.

Després de tants anys, I'Institut-Escola no és un tema nostàlgic, és vigent a casa nostra en àmbits com la Federació de Moviments de Renovació Pedagògica, sindicats, associacions de pares i mares... Tot i que a poc a poc i encara que sigui formalment (sense entrar en els projectes pedagògics), la implementació d'instituts-escola va endavant, per tal d'unificar en un mateix centre i equip directiu les etapes d'Infantil, Primària i Secundària. S'ha passat de crear-ne onze mentre era conseller d'Educació Ernest Maragall ${ }^{13}$ (XI-2006 / XII-2010) a vint-i-vuit instituts-escola durant el curs 2018-2019, i vint-i-cinc més per al 2019-20, essent conseller Josep Bargalló i Valls. Benvingudes aquestes i futures realitats que la comunitat educativa reclama cada vegada amb més intensitat.

\section{Referències}

Ainaud de Lasarte, J. M. (2011) Mestres que han fet Catalunya. Barcelona, Editorial Mediterrània.

Ainaud, J. M. i Domènech, S. (2007) Petita història de l'Institut-Escola de la Generalitat. Barcelona, Editorial Mediterrània.

Aisa, F. (2008) Mestres, renovació i avantguarda pedagògica a Catalunya. Barcelona, Edicions de 1984.

Alsina, À. i Planas, N. (2008) Matemática Inclusiva. Propuestas para una educación accesible. Madrid, Narcea.

Amics de I'Institut-Escola (1979) Vida i Obra del Dr. Josep Estalella 1879-1938. Vilafranca del Penedès, Gràfiques Tordera.

Avizanda i Martínez, M. (2007) L'Institut-Escola a Can Surell. Un assaig al Montseny dels anys trenta. Barcelona, ICE de la Universitat de Barcelona.

Baltà i Moner, J. (2017) Ciència i Tecnologia al Penedès. Passat, Present i Futur. Vol. I. Alt Penedès. Vilafranca del Penedès, Edita Heretat Baltà de Cela.

Baltà, J. i Domènech, S. (2017) «L'estada del doctor Josep Estalella a I'Institut de Girona (1905-1919)». Revista de Girona, núm. 305, p. 40-42.

Baltà, J. i Domènech, S. (2017) «Una relació d'amistat desconeguda. El Dr. Josep Estalella i Carles Rahola». Revista de Girona, núm. 305, p. 43-46.

Bastons, C. (2019) «Maria dels Àngels Ferrer i Sensat (1904-1992), una vida dedicada a l'educació». Temps d'Educació, núm. 56, p. 237-256.

(13) La seva mare, Basilisa Mira i Azorín, va estudiar a I'Instituto-Escuela de Madrid i el seu pare, Jordi Maragall i Noble, va exercir de professor a I'Institut-Escola de la Generalitat. 
Bertomeu Sánchez, J. R. i García Belmar, A. (Eds.) (2002) Abriendo las cajas negras. Colección de instrumentos científicos de la Universitat de València. València, Universitat de València i Fundació General de la Universitat de València.

Butlletins dels Alumnes dels Institut-Escola de Barcelona (1979) -edició facsímil dels butlletins Escola, Institut-Escola Pi i Margall i Butlletí de la Biblioteca dels Alumnes de l'Institut-Escola Pi i Margall en format de llibre-. Barcelona, Gràfiques Tordera.

Callís i Franco, J. (2007) «Les experiències de Ciència Recreativa, del Dr. Josep Estalella, i aprenentatge matemàtic». Scientia gerundensis, núm. 28, p. 89-103.

Capmany, Maria Aurèlia, La formació literària, «Grans Temes L'Avenç», núm. 2, juliol de 1979.

Capmany, Maria Aurèlia (1987) Mala memòria. Barcelona, Editorial Planeta.

Cardús, M. (1980) Josep Estalella i l'Institut-Escola. Barcelona, Ajuntament de Barcelona.

Cobos Bueno, J. Ma (2007) Eduardo Lozano y Ponce de León. Badajoz, Diputación de Badajoz.

De Saavedra, A. M. (1979) «Treballs literaris penedesencs» a Dr. Josep Estalella $i$ Graells. L'Obra Dispersa. Barcelona, Gràfiques Tordera.

Delgado Martínez, Ma A. (2009) Científicas y educadoras: las primeras mujeres en el proceso de construcción de la Didáctica de las Ciencias en España. Murcia, Servicio de Publicaciones Universidad de Murcia.

Domènech i Domènech, S. (1982) «L'Institut-Escola». Guix, núm, 55, p. 67-68.

Domènech i Domènech, S. (1983) «Josep Estalella i Graells». Guix, núm. 63, p. 51-53.

Domènech i Domènech, S. (1984) «Àngels Ferrer i Sensat: la renovació pedagògica». L'Avenç, núm. 71, p. 20-25.

Domènech i Domènech, S. (1998) L'Institut-Escola de la Generalitat i el doctor Josep Estalella. Barcelona, Publicacions de l'Abadia de Montserrat.

Domènech i Domènech, S. (1999) «L'Institut-Escola de la Generalitat i el doctor Josep Estalella». Fòrum, Fundació Caixa de Sabadell, p. 29-38.

Domènech i Domènech, S. (1999) «L'Institut-Escola de la Generalitat: un assaig d'ensenyament renovador». L'Avenç, núm. 237, p. 10-16.

Domènech i Domènech, S. (1999) «Josep Estalella i Graells: la renovació de I'ensenyament secundari». Escola Catalana, núm. 363, p. 30-31.

Domènech i Domènech, S. (2007) «Els ex-alumnes de I'Institut-Escola estan de festa». Escola Catalana, núm. 442, p. 45.

Domènech i Domènech, S. (2008) Els alumnes de la República. Els Grups Escolars de l'Ajuntament de Barcelona. Barcelona, Publicacions de l'Abadia de Montserrat.

Domènech i Domènech, S. (2008) «Josep Estalella i Graells i la Renovació Pedagògica», dins de La Renovació Pedagògica al Penedès, a L'Escola Nova: la República dels ciutadans petits. Vilafranca del Penedès, Vinseum, p. 22-36.

Domènech i Domènech, S. (2009) Els alumnes de la Generalitat. Els Institut-Escola republicans. Barcelona, Publicacions de l'Abadia de Montserrat.

Domènech i Domènech, S. (2018) «Los cuatro Institut-Escola de Cataluña» a Martínez, E.; López-Ocón, L. i Ossenbach, G. (Eds.), Ciencia e innovación en las aulas. Centenario del Instituto-Escuela (1918-1939). Madrid, CSIC-UNED, p. 273300. 
En el quarantè aniversari de la fundació de l'Institut-Escola 1932-1972 (1972) Barcelona, Tallers gràfics Ariel.

Estalella, J. (1930) Ciencia recreativa. Enigmas y problemas. Observaciones y experiencias. Trabajos de habilidad y paciencia. Barcelona, Ed. Gustavo Gili.

Estalella, J. (1931) Productes antiparasitaris. Barcelona, Tipografia Occitània.

Estalella i Graells, J. (1979) L'Obra Dispersa. Barcelona, Gràfiques Tordera.

Ferrer, A. i Martínez, M. (1987) Diàlegs a Barcelona. Barcelona, Ajuntament de Barcelona / Ed. Laia.

Galí, A. (1979) Història de les Institucions i del Moviment Cultural a Catalunya 19001936, Llibre III Ensenyament Secundari. Barcelona, Fundació A. G.

García-Molina, R. (2011) «Ciencia Recreativa: un recurso didáctico para enseñar deleitando». Revista Eureka sobre Enseñanza de las Ciencias, núm. 8 (extraordinari), p. 370-392.

Generalitat de Catalunya (1932) Règim de l'Institut-Escola. Barcelona, Tipografia Occitània.

Generalitat de Catalunya. (1982) Commemoració del 50è Aniversari de l'InstitutEscola (1932-1939). Cicle de conferències organitzat per l'Associació d'Amics de l'Institut-Escola. Barcelona, Impressió Seix y Barral.

Generalitat de Catalunya (1992) Institut-Escola 1932-1939. Barcelona, Gràfica Romero.

González-Agàpito, J. (1992) L'Escola Nova Catalana 1900-1939. Vic, Eumo.

Institut=Escola (1977) -reedició dels 22 números del butlletí Institut=Escola en format de llibre-. Perpinyà, Imp. Spe.5.

Jiménez-Landi Martínez, A. (1996) La Institución Libre de Enseñanza y su ambiente. III. Periodo Escolar (1881-1907). Madrid, MEC.

L'Avenç (1976) Grans temes l'Avenç. L'Institut-Escola: 1932-1939, Barcelona, núm. 2, p. 1-72.

Lozano Lucia, Ó. R. (2012) La ciencia recreativa como herramienta para motivar y mejorar la adquisición de competencias argumentativas. València, Universitat de València (tesi doctoral).

Marín Eced, T. (1991) Innovadores de la Educación en España. (Becarios de la Junta para Ampliación de Estudios). Cuenca, Servicio de Publicaciones de la Universidad de Castilla-La Mancha.

Mata i Garriga, M. (1999) «L'Institut-Escola del Parc de la Ciutadella. Un testimoni». Sabadell, Fòrum, Fundació Caixa de Sabadell, p. 21-24.

Monés i Pujol-Busquets, J. (1977) El pensament escolar i la renovació pedagògica a Catalunya (1833-1938). Barcelona, Edicions La Magrana.

Monzón Pinilla, C. i Usón Jaeger, A. (1997) «Propuestas didácticas innovadoras para la enseñanza de las ciencias físicas, químicas y naturales en el primer tercio del siglo XX en la escuela primaria española». Revista Complutense de Educación, vol. 8, núm. 1, p. 271-289.

Navarro, Ramon (1979) L'educació a Catalunya durant la Generalitat 1931-1939. Barcelona, Edicions 62.

Perspectiva Escolar (1982) El cinquantenari de l'Institut-Escola de la Generalitat (1932-1939), Barcelona, núm. 63, p. 1-57.

Portell, R.; Marquès, S. (2006) Els Mestres de la República. Barcelona, Ara Llibres. 
Portell, R. i Domènech, S. (2008) «L'institut dels valors». Sàpiens, núm. 63, p. 46-49. Quer i Büngeler, Emília (2005) Poemes i Anècdotes. Barcelona, Clivis Publicacions. Tissandier, G. (2010) La Física y la Química sin aparatos ni laboratorios y solo por los juegos de la infancia. Valladolid, Editorial Maxtor.

Vilafranca, I. i Vilanou, C. (Eds.) (2018) Giner i la Institución Libre de Enseñanza des de Catalunya. Cent anys després de la mort de Francisco Giner de los Ríos (18391915), Barcelona, Edicions de la Universitat de Barcelona.

Vilanou, C. i Soler, J. (1999) El Noucentisme: construir un país a través de l'educació, a Pedagogia a Catalunya. Barcelona, Fundació Jaume I, p. 30-43. 

secundaria

Resumen: Pocos docentes son recordados más allá del tiempo vital de su alumnado. Y aún menos los honorados dentro del campo de la Historia de la Educación. Uno de estos profesores privilegiados es el doctor Josep Estalella (1879-1938), por las aportaciones originales hacia la mejora de la metodología y la utilización de recursos didácticos. De la educación activa hizo el objetivo de su vida. Un talante voluntarioso y un vigor dirigente hicieron posible el cambio pedagógico en la educación secundaria catalana mediante el funcionamiento del Instituto-Escuela, paradigma de la renovación. Una de sus obras, Ciencia Recreativa..., cien años después de la publicación, aún es para el profesorado una herramienta didáctica valiosa para conseguir el objetivo inicial: llamar y captar la atención del alumnado mediante el juego intelectual.

Palabras clave: Josep Estalella, Instituto-Escuela, educación secundaria, ciencia, pedagogía, recreaciones científicas, Historia de la Educación.

\section{Josep Estalella $i$ Graells (1879-1938), le scientifique qui a réformé l'enseignement secondaire}

Résumé: On ne se souvient pas d'un grand nombre d'enseignants au-delà du temps vital de leurs élèves. Et encore moins de ceux qui ont reçu les honneurs dans le champ de l'histoire de l'éducation. Le docteur Josep Estalella (1879-1938) est l'un de ces professeurs privilégiés, en raison de ses contributions originales à l'amélioration de la méthodologie et à l'utilisation de ressources didactiques. Il a fait de l'éducation active l'objectif de sa vie. Son caractère délibéré et sa détermination de dirigeant ont permis le changement pédagogique dans l'enseignement secondaire catalan à travers le fonctionnement du lycée-école, paradigme de la réforme. L'une de ses œuvres, Ciencia Recreativa... (Science récréative), cent ans après sa publication, est encore pour le corps enseignant un outil didactique précieux pour atteindre l'objectif initial : attirer et capter l'attention des élèves au moyen du jeu intellectuel.

Mots clés: Formation universitaire, espace européen de l'enseignement supérieur (EEES), grade d'enseignement primaire, influence éducative.

\section{Josep Estalella i Graells: the scientist who helped reform secondary educa- tion}

Abstract: Few teachers are remembered beyond the lifetime of their students, and fewer still when their specialty is the history of education. But one exception to this rule is Dr Josep Estalella (18791938), whose lifelong involvement with active learning resulted in enduring contributions to teaching methodology and teaching resources. Estalella's commitment and leadership as director of the "Institut-Escola", the Government of Catalonia's progressive secondary school of the 1930s, made pedagogical change possible in Catalan secondary education. One hundred years after it was originally published, Estalella's Ciència Recreativa (Recreational Science) is still considered to be a valuable teaching resource for helping children develop intellectually through play.

Keywords: Josep Estalella, Institut-Escola, secondary education, science, pedagogy, scientific recreations, history of education. 